\title{
COMPARISON OF PHENOBARBITAL AND SODIUM VALPROATE FOR THE TREATMENT OF STATUS EPILEPTICUS IN CHILDREN.
}

1. MBBS

PGR (Pediatrics Medicine)

The Baqai University and Medical

College, Karachi.

2. FCPS (Pediatrics Medicine)

Assistant Professor Pediatrics

Medicine

Ghurki Trust Teaching Hospital, Lahore.

3. MBBS, FCPS

PGR (Pediatric Medicine)

The Children's Hospital and

The Institute of Child Health, Multan.

Correspondence Address:

Dr. Fazal Ur Rehman

The Children's Hospital and

The Institute of Child Health, Multan.

fazal171@gmail.com

Article received on:

$11 / 04 / 2019$

Accepted for publication:

$25 / 07 / 2019$

\begin{abstract}
Ameer Jamali', Waqas Ali ${ }^{2}$, Fazal Ur Rehman ${ }^{3}$
ABSTRACT... Objectives: Seizure is considered to be one of the commonest emergency involving more than half of the admissions in Pediatric Neurology wards. It has been well documented that proper management not only improves the prognosis but also decrease complications in these children. This study was planned to compare phenobarbital against sodium valproate for the treatment of status epilepticus (SE) in children. Study Design: Randomized clinical trial. Setting: Emergency Department of Pediatrics Medicine, the Baqai University and Medical College, Karachi. Period: $15^{\text {th }}$ July 2018 to $31^{\text {st }}$ December 2018. Material \& Methods: A total of 100 children (50 in each group) with seizure lasting longer than 5 minutes, aged 6 months to 12 years, did not respond to diazepam $(0.2 \mathrm{mg} / \mathrm{kg})$ within five minutes, were enroll. Randomization was done using lottery system where Group A was nominated who used sodium valproate and Group B, phenobarbital. Good response was labeled if a child's seizure was controlled within 20 minutes of treatment. Results: Out of total of 100 children included in the present study, there were $60(60.0 \%)$ male and $40(40.0 \%)$ female. Mean age of the children was 5.4 years with standard deviation of 2.2 years. As far as type of seizures are concerned, there were $43(43.0 \%)$ children presented with febrile convulsions (FC) while $57(57.0 \%)$ with SE. Overall, positive response was noted in 69 (69.0\%) children. Response in between both the groups turned out to be of statistical significance as more children, $40(80.0 \%)$ showed positive response in Group B in comparison to $29(58.0 \%)$ in Group A ( $p$ value $=0.017$ ). Amongst children with positive response, the difference between both the study groups was significant in relation to seizure types as $75.9 \%$ of children with SE showed positive response with sodium valproate while $52.5 \%$ children with FC showed positive response in Group B $(p$ value $=0.018$ ). Conclusion: Overall, both study drugs showed good positive response but phenobarbital when compared to sodium valproate is a better choice for controlling seizure in pediatric population. Sodium valproate showed greater effectiveness when used in children with SE while phenobarbital was comparatively more effective in febrile convulsion.
\end{abstract}

Key words: Phenobarbital, Sodium Valproate, Status Epilepticus, Seizure.

Article Citation: Jamali A, Ali W, Fazal Ur Rehman. Comparison of phenobarbital and sodium valproate for the treatment of status epilepticus in children. Professional Med J 2020; 27(7):1353-1357. DOI: 10.29309/TPMJ/2020.27.07.3543

\section{INTRODUCTION}

Seizure is described as paroxysmal and transient alteration in motor, behavioral and autonomic activity, progressing by interruption in brain electrical activity. ${ }^{1}$ Seizure is considered to be one of the commonest emergency involving more than half of the admissions in Pediatric Neurology wards. Prolonged seizure is related with increased mortality rates especially when complications like academia, hypoglycemia or hypotension are involved. It has been well documented that proper management not only improves the prognosis but also decrease complications in these children., ${ }^{2,3}$
A medical emergency is considered for seizures lasting more than 5 minutes if the patient doesn't wake up. ${ }^{1,4}$ Status Epilepticus (SE) should not be ruled out when patients are coming with acute seizure. SE is described as continuous seizure that lasts $>30$ minutes or $>2$ seizures without having complete recovery to consciousness if any one of these spanning for longer than 5 minutes. ${ }^{5}$ Previously, a cutoff time of 30 minutes was considered but that was minimized to highlight the risks related to longer durations. Febrile status epilepticus is a type of seizure that lasts for more than 30 minutes. ${ }^{1,5}$ 
An increased incidence of disorders related to seizures is reported in pediatric population in comparison to adults thus resulting in an increased use of anti-seizure medicines in pediatrics age groups. ${ }^{6}$ An ideal drug for seizure treatment should be the one that exhibits efficiency by reaching to brain quickly along with least adverse effects.

Benzodiazepines are considered to be the $1^{\text {st }}$ line treatment option for seizure in the emergency wards. ${ }^{7}$ It is recommended that a long acting antiseizure drug to be used if benzodiazepines do not succeed in treating seizure. Phenobarbital and phenytoin are considered to be the commonest $2^{\text {nd }}$ line anti-epileptic options in most developing countries. $^{8}$

In 1912, phenobarbital came on the screen as the $1^{\text {st }}$ anti-epileptic drug and even if today, it is frequently used for seizures. Phenobarbital is considered to be efficacious and less toxic while being cost effective makes it a handy option to be used. ${ }^{9}$ The evidence also suggest that Phenobarbital damages behavioral as well as cognitive activities while its usage during growth may contribute to harmful effect to memory and learning capacity of children. ${ }^{10}$

Sodium Valproate is a broad spectrum anticonvulsant which is widely used in our part of the world. It is considered to efficacious in various forms of seizure absence, tonic-clonic as well as myoclonic. ${ }^{11}$ Some studies have compared sodium valproate with phenytoin regarding SE control and found varying results where some saying that sodium valproate was found more efficacious while other concluded that there was no difference in between the two treatment groups in terms of control of seizure as well as duration of hospital stay or complications. ${ }^{11-13}$ Whereas, diazepam is evaluated to be better for handling children with SE in comparison to sodium valproate. ${ }^{14}$

Phenobarbital is considered effective but accompanies side effects while sodium valproate has shown good applicability but with conflicting results. We could not find any local study comparing the results of both these drugs so we planned this study to compare phenobarbital against sodium valproate for the management of SE in children.

\section{MATERIAL \& METHODS}

This randomized clinical trial was done in the Emergency Department of Pediatrics Medicine, The Baqai University and Medical College, Karachi, from $15^{\text {th }}$ July 2018 to $31^{\text {st }}$ December 2018. The study was approved by institutional ethical committee. A total of 100 children (50 in each group) with seizure lasting longer than 5 minutes, aged 6 months to 12 years, did not respond to diazepam $(0.2 \mathrm{mg} / \mathrm{kg})$ within five minutes, were enrolled using convenient sampling technique. Children with uncontrolled bleeding, any kind of liver disease, thrombocytopenia, heart diseases, and any kind of history using anti-convulsants, asthma or those with chronic liver disease or symptomatic epilepsy were not included in the study. Consent was sought from parents / guardians of all the study participants.

Randomization was done using lottery system where Group A was nominated as those children using sodium valproate and Group B as children using phenobarbital. Sodium valproate was administered as $20 \mathrm{mg} / \mathrm{kg}$ as IV infusion whereas phenobarbital was also $20 \mathrm{mg} / \mathrm{kg}$ as IV infusion. Good response was labeled if a child's seizure was controlled within 20 minutes of treatment.

Demographic data like age, gender, history of past seizure and types were noted. Recovery time after administration of both drugs was also recorded. Data was handled and analyzed using SPSS version 20.0. Chi square test was applied for comparing qualitative study variables whereas independent sample t test was used to compare variables which were quantitative in nature. $P$ value less than 0.05 was considered to be statistically significant.

\section{RESULTS}

Out of total of 100 children included in the present study, there were 60 (60.0\%) male and 40 (40.0\%) female. Mean age of the children was 5.4 years with standard deviation of 2.2 years. As far as type 
of seizures are concerned, there were 43 (43.0\%) children presented with febrile convulsions (FC) while 57 (57.0\%) with SE. Overall, positive response was noted in 69 (69.0\%) children.

When both groups were compared for different study variables, there was no difference in terms of statistical difference for gender, type of seizure, age, and response time $(p>0.05)$. Response in between both the groups turned out to be of statistical significance as more children, 40 $(80.0 \%)$ showed positive response in Group B in comparison to 29 (58.0\%) in Group A ( $p$ value $=0.017$ ). Mean response time in Groups $A$ was $6.37+1.2$ minutes in comparison to $5.99+1.2$ in Group B ( $p$ value $=0.673$ ).

Amongst 69 children who showed positive response, the difference between both the study groups was significant in relation to seizure types as $75.9 \%$ of children with SE showed positive response with sodium valproate while $52.5 \%$ children with FC showed positive response in Group B ( $p$ value $=0.018)$.

\section{DISCUSSION}

We noted that children in phenobarbital group better positive response in comparison to those children who were administered sodium valproate. It was also noted that patients with FC showed better response in phenobarbital group while children with SE showed much better response with sodium valproate. This meant that different type of seizures response differently when handled with different drugs. It has been shown in the past ${ }^{15}$ as well that when presented with SE, sodium valproate is more effective than phenobarbital which correlates to this present work. Not many studies have compared sodium valproate and phenobarbital for seizure control in children so this study was supposed to be a valuable addition to existing knowledge about these two drugs. A recent study from $\operatorname{Iran},{ }^{4}$ comparing phenobarbital and sodium valproate for controlling seizure in children proved that response of these two drugs was different for different type of seizures which again correlates strongly with our study.

\begin{tabular}{|c|c|c|c|}
\hline \multirow{2}{*}{ Study Variables } & \multicolumn{2}{|c|}{ Groups } & \multirow{2}{*}{ P-Value } \\
\hline & Sodium Valproate $(n=50)$ & Phenobarbital $(n=50)$ & \\
\hline \multicolumn{4}{|c|}{ Gender } \\
\hline Male & $31(62.0 \%)$ & $29(58.0 \%)$ & \multirow{2}{*}{0.683} \\
\hline Female & $19(38.0 \%)$ & $21(42.0 \%)$ & \\
\hline \multicolumn{4}{|c|}{ Types of Seizure } \\
\hline Febrile Convulsion & $21(42.0 \%)$ & $22(44.0 \%)$ & \multirow{2}{*}{0.840} \\
\hline Status Epilepticus & $29(58.0 \%)$ & $28(56.0 \%)$ & \\
\hline Age in Years (Mean+SD) & $5.58+2.1$ & $5.20+2.2$ & 0.654 \\
\hline $\begin{array}{l}\text { Response Time in minutes } \\
(\text { Mean+SD) }\end{array}$ & $6.37+1.2$ & $5.99+1.2$ & 0.673 \\
\hline \multicolumn{4}{|c|}{ Response } \\
\hline Positive & 29 (58.0\%) & $40(80.0 \%)$ & \multirow{2}{*}{0.017} \\
\hline Negative & $21(42.0 \%)$ & $10(20.0 \%)$ & \\
\hline
\end{tabular}

\begin{tabular}{|l|c|c|c|}
\hline \multirow{2}{*}{ Type of Seizure } & \multicolumn{2}{|c|}{ Groups } & \multirow{2}{*}{ P-Value } \\
\hline & Sodium Valproate $\mathbf{( n = 2 9 )}$ & Phenobarbital $(\mathbf{n = 4 0 )}$ & \multirow{2}{*}{0.018} \\
\hline Febrile Convulsions & $7(24.1 \%)$ & $21(52.5 \%)$ & \\
\hline Status Epilepticus & $22(75.9 \%)$ & $19(47.5 \%)$ & \\
\hline \multicolumn{2}{|r|}{ Table-III. Relation of Positive Response and Types of Seizures in Both Groups (n=69) } \\
\hline
\end{tabular}


They showed that overall; phenobarbital treated children had more rapid response for seizure control while phenobarbital was more effective when used for generalized or partial seizures while sodium valproate highlighted better effects when used for controlling SE.

Sodium valproate has been compared with phenytoin in children suffering with SE and the mean response time taken by sodium valproate was much lesser as compared to phenytoin, again showing the effectiveness of sodium valproate. ${ }^{16}$ Adult population have been shown to have slightly better response of phenytoin in comparison to sodium valproate (68\% vs $66 \%$ ) for seizure control while more recently sodium valproate was analyzed as a better option while considering anticonvulsant for treating SE. ${ }^{17}$

Primary goal of treating children with seizure is to fully control the seizures in between 20 minutes of starting an anticonvulsant therapy in the form of infusion. IV sodium valproate has been advocated as $1^{\text {st }}$ choice when treating SE and acute seizures in pediatric population while it has also been documented that with an increase in children's age, the response time taken by the drug also increases. ${ }^{18}$

In the present study, we noted a good overall response of both drugs as $2^{\text {nd }}$ line treatment for seizures in children. It was noted that sodium valproate showed good response against SE while phenobarbital was more efficacious when the seizure type was generalized or partial.

\section{CONCLUSION}

Overall, both study drugs showed good positive response but phenobarbital when compared to sodium valproate is a better choice for controlling seizure in pediatric population. Sodium valproate showed greater effectiveness when used in children with SE while phenobarbital was comparatively more effective in febrile convulsion. Copyright@ 25 July, 2019.

\section{REFERENCES}

1. Kliegman R, Behrman R, Jenson H, Stanton B. Seizure in childhood. In: Mikati MA, Hani AJ, editors. Nelson Textbook of Pediatrics. 19th ed. Philadelphia: Elsevier Science; 2016.p.4297.

2. Ashrafi MR, Khosroshahi N, Karimi P. Efficacy and usability of buccal midazolam in controlling acute prolonged convulsive seizures in children. Eur $\mathrm{J}$ Paediatr Neurol 2010; 14: 434-438.

3. Serdaroglu A, Ozkan S, Aydin K, Gucuyener K, Tezcan $S$, Aycan S. Prevalence of epilepsy in Turkish children between the ages of 0 and 16 yr. J Child Neurol 2004; 19(4):271-4.

4. Khajeh A, Yaghoubinia F, Yaghoubi S, Fayyazi A, MiriAliabad GH. Comparison of the Effect of Phenobarbital versus Sodium Valproate in Management of Children with Status Epilepticus. Iran J Child Neurol. Autumn 2018; 12(4):55-93.

5. Mazurkiewicz-Bełdzińska M, Szmuda M, Zawadzka M, Matheisel A. Current treatment of convulsive status epilepticus-a therapeutic protocol and review. Anesthesiology Intensive Therapy 2014; 46:293-300.

6. Saneto RP, Kotagal P, Rothner DA, Baker J, Kotagal LL. Valproic acid use in pediatric partial epilepsy after initial medication failure. J Pediatt Neurol 2004; 2(4):109-203.

7. Treiman DM, Meyers PD, Walton NY. A comparison of four treatments for generalized convulsive status epilepticus. Veterans affairs status epilepticus cooperative study group. N Engl J Med 1998; 339:792798.

8. Trinka E. The use of valproate and new antiepileptic drugs in status epilepticus. Epilepsia 2007; 48(Suppl. 8):49-51.

9. Walia KS, Khan EA, Ko DH, Raza SS, Khan YN. Side effects of antiepileptics: A review. Pain Pract 2004; 4: 194-203.

10. Rho JM, Sankar R. The pharmacologic basis of antiepileptic drug action. Epilepsia 1999; 40: 1471-83.

11. Misra UK, Kalita J, Patel R. Sodium valproate vs. phenytoin in status epilepticus: a pilot study. Neurology 2006; 67: 340-342.

12. Somsak T, Kittisak S, Alongkorn Ch. The efficacy of intravenous sodium valproate and phenytoin as the first-line treatment in status epilepticus: a comparison study. BMC Neurol 2013, 13(2)140-5. 
13. Malamiri RA, Ghaempanah M, Khosroshahi N, Nikkhah A, Bavarian B, Ashrafi MR. Efficacy and safety of intravenous sodium valproate versus phenobarbital in controlling convulsive status epilepticus and acute prolonged convulsive seizures in children: a randomized trial. Eur J Paediatr Neurol 2012; 16(5): 536-41.

14. Mehta V, Singhi $P$, Singhi S. Intravenous sodium valproate versus diazepam infusion for the control of refractory status epilepticus in children: a randomized controlled trial. J Child Neurol 2007; 22(10):1191-7.

15. Malamiri RA, Ghaempanah M, Khosroshahi N, Nikkhah A, Bavarian B, Ashrafi MR. Efficacy and safety of intravenous sodium valproate versus phenobarbital in controlling convulsive status epilepticus and acute prolonged convulsive seizures in children: a randomized trial. Eur J Paediatr Neurol 2012; 16(5): 536-41.
16. Somsak T, Kittisak S, Alongkorn C. The efficacy of intravenous sodium valproate and phenytoin as the first-line treatment in status epilepticus: a comparison study. BMC Neurol 2013, 13(2)140-5.

17. Kanner AM. The pharmacology of parenteral valproate. Epilepsy Curr 2003; 3:109-111.

18. Chang YC, Lin JJ, Wang HS, Chou ML, Hung PC, Hsieh MY. Intravenous valproate for seizures in 137 Taiwanese children - valproate naive and non-naive. Acta Neurol Taiwan 2010; 19(2): 100-6.

\begin{tabular}{|c|c|c|c|}
\hline \multicolumn{4}{|c|}{ AUTHORSHIP AND CONTRIBUTION DECLARATION } \\
\hline Sr. \# & Author(s) Full Name & Contribution to the paper & Author(s) Signature \\
\hline 1 & Ameer Jamali & $\begin{array}{l}\text { Methodology, Data collection, } \\
\text { Literature review. }\end{array}$ & \\
\hline 2 & Waqas Ali & $\begin{array}{l}\text { Methodology, Literature review, } \\
\text { Discussion, Drafting Proof } \\
\text { reading. }\end{array}$ & cus \\
\hline 3 & Fazal Ur Rehman & $\begin{array}{l}\text { Methodology, Literature review, } \\
\text { Data analysis, Drafting. }\end{array}$ & 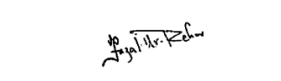 \\
\hline
\end{tabular}

